Article

\title{
Supra-Regional District Heating Networks: A Missing Infrastructure for a Sustainable Energy System
}

\author{
Simon Moser ${ }^{1, *(1)}$ and Stefan Puschnigg ${ }^{2}$ \\ 1 Department of Energy Economics, Energy Institute at the Johannes Kepler University, A-4040 Linz, Austria \\ 2 Department of Energy Technology, Energy Institute at the Johannes Kepler University, A-4040 Linz, Austria; \\ puschnigg@energieinstitut-linz.at \\ * Correspondence: moser@energieinstitut-linz.at
}

check for updates

Citation: Moser, S.; Puschnigg, S. Supra-Regional District Heating Networks: A Missing Infrastructure for a Sustainable Energy System. Energies 2021, 14, 3380. https:/ / doi.org/10.3390/en14123380

Academic Editors: Anna Volkova, Hanne Kauko and Sanna Syri

Received: 6 May 2021

Accepted: 7 June 2021

Published: 8 June 2021

Publisher's Note: MDPI stays neutral with regard to jurisdictional claims in published maps and institutional affiliations.

Copyright: (c) 2021 by the authors. Licensee MDPI, Basel, Switzerland. This article is an open access article distributed under the terms and conditions of the Creative Commons Attribution (CC BY) license (https:/ / creativecommons.org/licenses/by/ $4.0 /)$.

\begin{abstract}
In analogy to electricity transmission networks, this paper analyzes the concept of supraregional district heating networks (SR-DHN), connecting a large number of actors. Using a backcasting approach, a SR-DHN is assumed to exist and thus, implementation challenges, such as economic feasibility and energy losses, are circumvented in the first step (but are analyzed in the discourse). The paper then analyzes, in an interdisciplinary qualitative manner and supported by a case study, what technical, operational, economic and legal issues must have been resolved. Results show that the heat transmission network, being the backbone of the SR-DHN, is an expensive infrastructure, but is likely to become economic in a non-fossil energy system. By decreasing the reliance on single waste heat sources, SR-DHN allows longer payback periods and can thus be an enabler for using industrial waste heat. However, involving many actors requires comprehensive contractual foundations. The derived hypothesis is that SR-DHN, which is predominantly fed by waste heat, shall be operated with lower temperatures in winter (feeding the return while minimizing expensive winter losses) and high temperatures in summer (enabling alternative usages while accepting high but inexpensive summer losses).
\end{abstract}

Keywords: district heating; waste heat; energy cooperation; industrial symbiosis

\section{Introduction}

There are supra-regional electricity networks; they are connecting many generation, storage and consumption units, which are operated and owned by a multitude of economic actors. In Europe, the intercontinental network reaches from Portugal to Poland and from Norway to Turkey. The development towards distinctive distributions networks and transmission lines, as we know them today, started from very small and local electricity networks. By connecting the individual networks, synergy potential was raised. The resulting trend towards economies of scale seems evident, for example with large power plants in the gigawatt output range and large-scale pumped storage units, which would not fit into a small (locally limited) power network [1]. In the course of the energy transition, which brings with it a decentralization and fluctuation of generation, today's large network forms the backbone of the potential to feed-in these renewables. This does not intend to downplay the problems of high proportions of renewable energy feed-in, but means, for example, that integrating a single PV plant is definitely less complex than integrating it into a small island network.

With the long-term perspective of a renewable and highly efficient sustainable energy system, the recovery and reuse of decentralized and fluctuating (industrial) waste heat become essential. In conclusion, this energy source, which will become much more relevant in a sustainable/decarbonized heating sector, has similar characteristics to those that are becoming relevant in the electricity sector. However, district heating networks are locally limited infrastructures, with a usual diffusion in the respective dense urban area. The local limitations imply that the potential for heat feed-in is limited. Problems include: 
- Excess of industrial waste heat in many times of the year: industrial waste heat potentials are relevant for the whole year, but are especially high in summer [2].

- Urban land prices are price drivers for production (and storage units enabling the shift of usage of the available heat): [2] found that urban land prices could be the trigger for economic infeasibility of seasonal storages, when waste heat is available within the city boundaries.

- Low opportunities for the efficient supply of waste heat from remote plants in rural areas to potential customers in distant cities: bilateral connections are always less efficient than those being used by many actors (network principle: the more actors use a network infrastructure, the less expensive it gets for the single actor).

- Unavailability of inexpensive heat and therefore no district heating systems in rural and in many urban areas: if waste heat is provided cost-effectively, it can also contribute to economic district heating systems in low-density areas [3].

The aim of this paper is to analyze the implications of a hypothetical transfer of supraregional electricity networks to the district heating sector, i.e., the conceptual creation of supra-regional district heating networks (SR-DHN). A heat transmission network constitutes the backbone of this system (in accordance to the electricity network's transmission lines) and is in the focus of the analysis. A back-casting approach is applied: an SR-DHN is assumed to exist. It is then analyzed, in an interdisciplinary qualitative manner and supported by a case study, what technical challenges, system operation, financing, revenue flows, legal and contractual issues, etc., must have been resolved. With the back-casting approach, a planner's challenges, especially the general economic feasibility and the expected pipe losses, are circumvented in the first step, but will be analyzed in the discourse.

Electricity networks and gas networks (including the potential to absorb synthetic methane and hydrogen in future scenarios) are available; high-exergy fuels like oil or biomass can cost-effectively be transported via rail, ship or road. At the same time, there is no infrastructure or other systems for transporting low-exergy energy over long(er) distances, while many of the energy potentials in a future sustainable energy system are low-exergy (geothermal, solar thermal, waste heat, heat pumps utilizing ground sources or similar). Future sustainable energy scenarios clearly point out the importance of district heating and the use of low-exergy sources, especially from industrial and CHP waste heat [4]. Piacentino et al. [5] also stress out district heating, using renewable energy sources and waste heat as a key technology for a sustainable heat supply, but emphasizes the capability of distributing heat between supplier and consumer as enabler. From this, it is derived that SR-DHN can be an appropriate solution in future sustainable energy systems, implying the need to consider them theoretically for the first time.

Although there are similar concept implementations of SR-DHN, for example in Copenhagen, Rhein-Ruhr or Innsbruck (see Section 3.2 below), the topic of SR-DHN is hardly considered in scientific literature. This paper aims to create a theoretical basis for the implementation of multi-actor SR-DHN, interlinked by the superior heat transmission network, and to look at SR-DHN from a systemic and interdisciplinary perspective. Due to the systemic nature of the analysis, there are hardly provisions on methods to be applied. The novelty of the paper is that it is the first to

- introduce a definition of SR-DHN,

- identify heat transmission pipelines and similar-concept implementations,

- describe general characteristics of SR-DHN regarding systemic, technical and economic aspects, and

- derive the research questions to be addressed in order to support the implementation of SR-DHN.

\section{Materials and Methods}

In the following, a definition for analyzing SR-DHN is derived, and the methods applied are presented. 


\subsection{Definition}

Supra-regional district heating network (SR-DHN) shall be defined to traverse suburban or rural areas, interconnecting multiple (i) industrial waste heat and other sustainable sources, (ii) one or more district heating networks (where regular district heating network final customers are situated) and stand-alone major customers, (iii) industrial process heat sinks, and/or (iv) thermal storage facilities.

Therefore, this paper understands SR-DHN in an analogy with the high-voltage electricity transmission network. The concept of SR-DHN investigated here shall go far beyond the state-of-the-art in terms of supra-regionality, bidirectional interconnection, and number of independent economic players acting, feeding or consuming from the SR-DHN. An exemplary scheme pf a SR-DHN, interlinked by the heat transmission network, which constitutes the backbone, is illustrated in Figure 1.

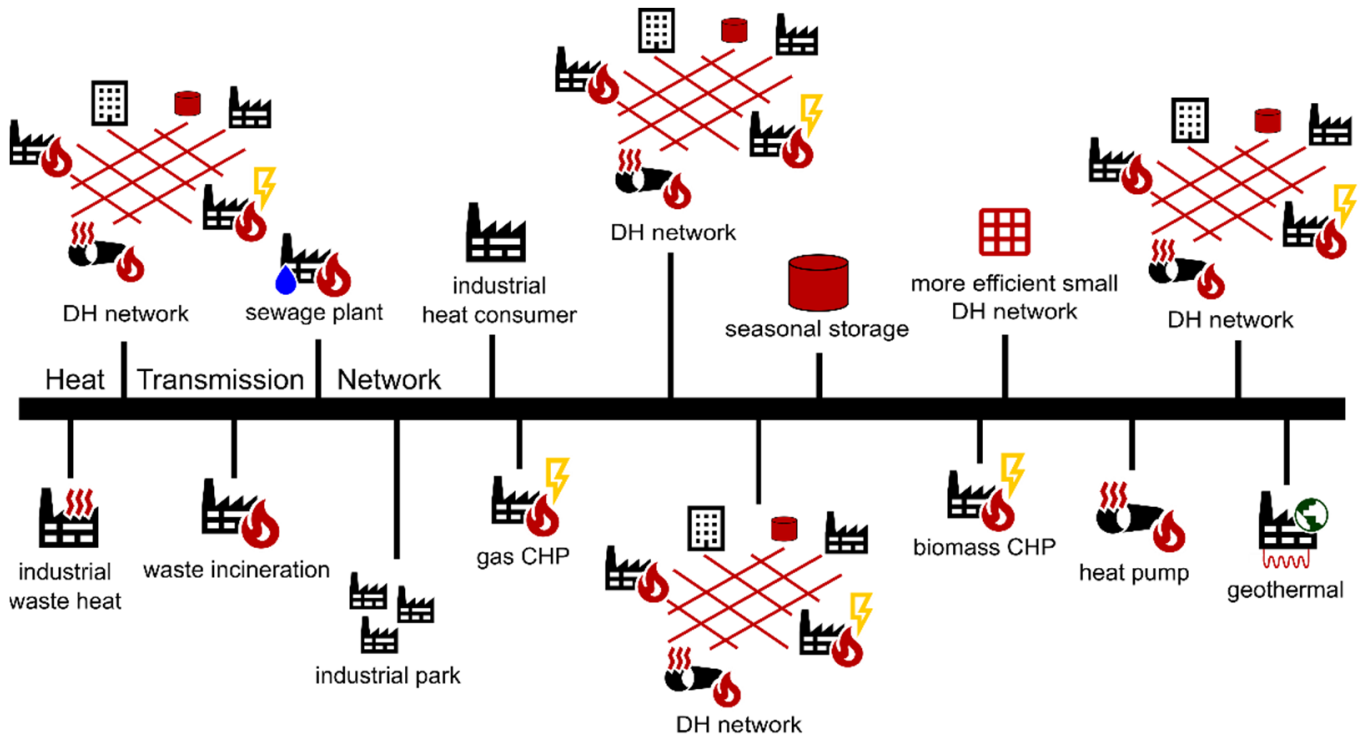

Figure 1. Scheme of a supra-regional district heating network (SR-DHN), interlinked by the superior heat transmission network, which constitutes the backbone. The scheme is based on existing and contemplated components of the case study described in Section 4.1.

There is a limited number of SR-DHN existing in practice (see below in the status quo analysis). Moreover, there are many district heating networks that are close to match the definition, for example, district heating networks with primary and secondary levels (e.g., Vienna) or district heating networks that are close to each other and have grown together. Others, but definitely out of the scope of the definition, are long-distance feed-only pipelines, as they can be observed in Linkoping or St. Pölten, just to name two examples (see Table 1 later). These are long feed-only pipelines, i.e., they are a one-way connection of a remote generation site and a district heating network, and do not interconnect more players.

\subsection{Approach and Methods Applied}

SR-DHN, according to the definition given above, is hardly considered in scientific literature. As said before, due to the systemic nature of the analysis, there are hardly provisions on methods to be applied. Therefore, a wide range of different assessment methods were chosen.

Literature research forms the basis of the applied methods. However, due to the small number of examples and different drivers, the literature research does not deliver a generalizable statement on the connection of several existing district heating networks. Therefore, the literature research focused on comparable solutions, i.e., the analysis of existing long-distance pipelines and the first approaches to practical implementation of SR-DHN in Europe. Furthermore, based on literature research, the method of content com- 
parison was carried out, specifically between the effects of a power transmission network and what such a transfer to district heating would mean. The comparative content analysis describes the parameters of the two concepts, arranged according to categories. These categories were filled on the basis of literature analyses and the involvement of experts.

Interviews were conducted with several companies, especially district heating network operators in Austria, who deal with long-distance lines (e.g., $10 \mathrm{~km}$ and more) or the first sub-aspects of SR-DHN in the following chapter (Status Quo Analysis). Furthermore, interviews were carried out with several companies (industry, plant manufacturers). In total, inputs were received from 14 different stakeholders.

For the industrialized state of Upper Austria, SR-DHN should be clearly illustrated. A case study was therefore carried out for the state. In this case study, existing data sets on heat sources (heating plants, combined-heat-and-power (CHP) systems, industrial waste heat) and heat sinks (existing heat networks) were used to define the optimal route of the SR-DHN. Time-resolved energy flows, as well as calculations of the actual total amounts of energy, were not yet part of this study.

Two workshops formed a central component of the applied methods. The first one was carried out with a total of 20 participants, coming from district heating operators, industrial companies and institutions. This workshop provides stakeholder arguments and, in some respects, are applicable for countries with a significant share of district heating; partial results are generalizable. Furthermore, concrete statements on an Upper Austria case study were considered in this workshop. A second workshop dealt with the transfer of knowledge when it comes to electricity transmission networks to SR-DHN. The four scientific participants discussed the comparability, based on basic economic principles, e.g., economies of scale, infrastructure availability, etc.

\section{Status Quo Analysis}

In this section, the status quo framework of SR-DHN is analyzed. First, existing district heating transmission feed pipelines are summarized; then, first existing or similar concept SR-DHN is presented; finally, the opportunities to integrate industrial waste heat into the (district) heating sector are briefly addressed.

\subsection{Large District Heating Transmission Pipelines in Europe}

The long-distance heat transmission feed pipelines considered in this section are supply lines to a district heating distribution network, which therefore connect source and sink over a greater distance. It is not a connection of several networks, and the integration of several sources is not the focus here. Still, from experiences with these feed pipes, findings from these supply lines can be deduced, e.g., which distances are economical and which amounts of energy can be transported with which pipe diameters. Existing heat transmission pipelines in Europe are summarized in Table 1.

The longest pipeline in Central Europe is in the capital of the federal state of Lower Austria and connects it to the Dürnrohr power plant park. Several cogeneration plants (biomass, gas, previously coal) are located in Dürnrohr. The route leads over $31 \mathrm{~km}$ and is, in any case, the longest in Austria, transporting 200 GWh each year. During transport, there is an operating temperature of up to 140 degrees and 40 bar pressure [6]. The losses over the entire $31 \mathrm{~km}$ route are only two degrees Celsius. Comparable implementations with long-distance lines in Austria can be found at the Sappi paper mill in Gratkorn [7], which is connected to the city of Graz with $11 \mathrm{~km}$ long pipeline [8]. The Arnoldstein waste incineration plant is connected to the city of Villach by a $16 \mathrm{~km}$ pipeline [9]. At the voestalpine steelworks in Donawitz, an $8 \mathrm{~km}$ long pipeline leads to the municipality of Trofaiach [10]. The city of Salzburg is connected to the city of Hallein via a $19 \mathrm{~km}$ pipeline; two district heating networks are also connected here, but the transport takes place in one direction only, which is why this case is also subsumed under supply lines [11]. These Austrian cases are relevant for the preliminary calculation of the investment costs of the Upper Austrian case study. 
Table 1. District heating transmission pipelines in Europe [12].

\begin{tabular}{ccccc}
\hline City & Country & Capacity [MW] & Length [km] & Diameter [mm] \\
\hline Linkoping-Mjolby & Sweden & 25 & 28 & - \\
Lindesberg & Sweden & 26 & 17 & - \\
Oslo & Norway & 275 & 20 & 600 \\
Helsinki & Finland & 490 & 25 & 1000 \\
Turku & Finland & 340 & 25 & 800 \\
Tilburg & Netherlands & 170 & 8.5 & 500 \\
Diemen-Almere & Netherlands & 260 & 10 & 500 \\
Almere & Netherlands & 170 & 12 & - \\
Viborg & Denmark & 58 & 86.3 & - \\
Oradea & Romania & 546 & 62 & 400 \\
Akranes & Iceland & 60 & 20 & - \\
Aachen & Germany & 85 & 1.1 & - \\
Gothenburg-Mölndal & Sweden & 10 & 22 & - \\
Gothenburg-Kungälv & Sweden & 19 & 15 & 800 \\
Lippendorf-Leipzig & Germany & 300 & 21.2 & 300 \\
Mannheim-Speyer & Germany & 40 & 16 & 400 \\
Boxberg-Weißwasser & Germany & 40 & 28 & 500 \\
Zolling-Flughafen & Germany & 150 & 27 & 800 \\
München & Iceland & 290 & 16.5 & 500 \\
Nesjavellir-Riykjavik & Greece & 137 & 31 & 425 \\
Kozani & Austria & 50 & & \\
St. Pölten & & & & \\
\hline
\end{tabular}

\subsection{SR-DHN in Europe}

Most technical or technological solutions already exist for realizing SR-DHN in general, and for this research specifically. Thus, naturally, whenever a clear business case for a specific actor arises, implementations are feasible and straightforward. It is found that some networks in Europe fit the definition of SR-DHN, at least in parts (e.g., connection of distant networks, number of actors involved). Exemplary implementations of SR-DHN are the following:

- $\quad$ Prague district heating network is fed by Melník 1 lignite-fired CHP plant located 38 km north [13]. Overall, 340 MW are brought to Prague, Mělník and Horní Počaply. Existing district heating generation plants were integrated into the pipeline. South of Prague, 49 local district heating networks were merged and connected [14].

- Innsbruck-Wattens is $20 \mathrm{~km}$ long [15] and embraces many distributed feeders (Duktus steel pipe, Wattens paper, Hall biomass, Innsbruck sewage treatment, etc.) and many distributed district heating sinks (Wattens, Hall, many small networks in Innsbruck) [16]. The SR-DHN provides 127.5 GWh/a [17].

- Since 1980, a SR-DHN over $80 \mathrm{~km}$ supplies heat to the cities of Kolding, Fredericia, Middelfart and Vejle in Denmark. The SR-DHN is jointly operated by 8 district heating companies and distributes around 1400 GWh of heat annually, which comes from waste incineration, refineries and CHP power plants [18].

- The Copenhagen SR-DHN is arguably the one that best fits the definition given in this paper. It arose from the fact that several networks were existing and situated close to each other; furthermore, they are yet unconnected and (not too) remote generation capacities (power plant waste heat) were available. The network now connects around twenty distribution networks and provides around $8.3 \mathrm{TWh} / \mathrm{a}$. The organizational implementation of the transmission system is that production, transmission and distribution are divided into three different operational areas [19].

- Rhein-Ruhr is definitely the largest example of an exemplary SR-DHN, however still in a conceptual phase. Rhein-Ruhr is an interconnection of the already existing large networks Niederrhein and Ruhr [20]. Niederrhein primary district heating network is $40 \mathrm{~km}$ long [21], the distribution network $500 \mathrm{~km}$ [22]. The Ruhr district heating 
network supplies $2300 \mathrm{GWh}$ of heat over $600 \mathrm{~km}$, which are fed into the SR-DHN through CHP plants and waste incineration plants [23]. The region of NordrheinWestfalen has 25 district heating networks [24]. By linking the two regional networks of Niederrhein and Ruhr, the largest European SR-DHN is to be created. The existing district heating networks in Niederrhein and Ruhr are to be gradually linked in five individual projects [20]. The final decision is still open.

- Another example from Denmark is the pipe from the Studstrupvaerket CHP plant to the city of Aarhus with about $20 \mathrm{~km}$ [25]. Another example in Germany is the $19 \mathrm{~km}$ network/pipeline from Saarlouis to Völklingen [26].

\subsection{Waste Heat Integration in the Context of District Heating}

Utilization of industrial waste heat within the company is a rather common practice, whereas the external use is less common. However, it is shown that, in many cases, the external use of waste heat is technically and economically feasible: for example, in Austria, 42 implementations providing industrial waste heat to district heating operators were identified. They have a capacity of $600 \mathrm{MW}$ and deliver $1.75 \mathrm{TWh} / \mathrm{a}$. The amounts observed imply that $2 \%$ of industrial energy end use are reused and provide $7.3 \%$ of district heating energy. Nevertheless, significant technical potentials remain [27].

In future energy systems, waste heat should account for a substantial share of space heating demand, in order to avoid the usage of high-quality renewable energies [28]. Space heating is likely to be the main use of industrial waste heat that cannot be used internally; of course, other uses are possible and may be advantageous from an exergy perspective (especially for waste heat at higher temperatures, i.e., for provision of process heat), season perspective (waste-heat-to-cold) or infrastructure perspective (heat-to-power for remote sources of waste heat) [27].

A large number of barriers stand in the way of the implementation of waste heat cooperation between a company and a district heating network operator. In this context, barriers from the area of information asymmetry are particularly relevant: the district heating network operator does not know (i) when the company is considering process modifications that would reduce the waste heat, or (ii) the exact financial status of the company (bankruptcy) or (iii) the status of the production site (relocation). These three areas would lead to a loss of the waste heat source and result in sunk costs for the investments in recovery, pipes and coupling points. Given information asymmetry between the cooperation partners, the likelihood of relocation or process modification is to be regarded as lowest if the process is newly installed or comprehensively modernized; thus, this is the ideal time to start waste heat cooperation.

\section{Results}

The results are divided into four subsections. First, the results of the Upper Austrian case study are presented. Second, based on the idea explained in the introduction section that the concept of SR-DHN is transferred from electricity transmission networks, a comparative analysis was performed. Third, specific issues are discussed or investigated in the case study; the workshops or the desk research analyses are presented, subdivided in technical (Section 4.3) and non-technical (Section 4.4) results.

\subsection{Case Study SR-DHN Upper Austria}

The Upper Austria industry is key to the performance of the entire (Upper) Austrian economy. The relevant production and welfare impact of industry makes Upper Austria an important industry location: "Upper Austrian industry produced material goods worth Euro 46.14 billion in 2015. Within Austria, this is the highest value and corresponds to a relative share of the total production value of $27.33 \%$. Upper Austria has the highest industrial density in the federal state comparison with $62.14 \%$ " [29].

As part of the European Energy Efficiency Directive (2012/27/EU), all EU member states had to carry out a comprehensive assessment of the potential for the use of highly 
efficient cogeneration plants and efficient district heating and cooling in the respective country. In the case study, the existing waste heat potential in Upper Austria was examined based on the tabular data from the power plants and industrial companies of the Austrian Heat Map [30]. The existing district heating networks were considered as heat sinks.

During the analysis conducted, the examined Upper Austrian industrial companies with possible waste heat potential were listed. For more detailed analysis and to determine the available waste heat output and the waste heat temperature level in summer and in winter, many industrial companies were interviewed by telephone. The results show only a low level of detail due to the telephone inquiry, i.e., details on profiles, failure rates, temperature profiles, development costs, etc. are missing. Taking into account the above-mentioned restrictions, the total waste heat potential of these companies is estimated at around $230 \mathrm{MW}$ in summer and $130 \mathrm{MW}$ in winter. There is further potential from thermal power plants and waste incineration plants (approx. $200 \mathrm{MW}$ ). Furthermore, the two largest industrial companies were estimated with a minimum potential, as they do not indicate any (economic) waste heat potential; if their waste heat potential was $1 \%$ of their energy end use, the mentioned industrial waste heat potential would be double.

The list of Upper Austrian thermal power plants was derived from the tabular data of the Austrian Heat Map. Two main assumptions were made: (a) the nominal thermal output is the same in summer and winter, (b) naturally, the available temperature level of the thermal power plant is sufficient to feed the SR-DHN, also at high temperatures.

Figure 2 shows the visualization of an SR-DHN in Upper Austria with the identified companies with expected waste heat potential, CHP plants and regional district heating networks. In order to promote the increased use of waste heat, an SR-DHN would support this issue by connecting heat sources and sinks to an overall heat infrastructure. The case study SR-DHN connects several district heating networks, industrial companies and thermal power stations and, starting from Linz as a base, would extend in a western direction via Wels to Vöcklabruck and Gmunden, and in an eastern direction via Enns to Steyr. The proposed route, which is provisionally marked in red, is based on the high density of generation and consumption in this region. The total length of the SR-DHN is about $130 \mathrm{~km}$ (as shown). It should be noted that the connecting pipes from the network to the individual companies or district heating networks, and the length of the district heating network itself with the various distribution levels, are not included in this figure. Furthermore, the existing producer and consumer structure gives the possibility to establish a shorter SR-DHN in the Ried area.

\subsection{Comparison with Electricity Transmission Networks}

Electricity networks can efficiently transport energy over large distances. A distinction is made between direct current transmission networks (HVDC - high voltage direct current lines, $>400 \mathrm{kV}$ ) and alternating current transmission networks (HVAC-high voltage alternative current lines, 220-380 kV). Compared to the electrical transmission networks, heat networks have so far largely been locally bound (radius $<30 \mathrm{~km}$ ). Heat networks are clearly inferior in terms of distance and capacity. However, the district heating and district cooling sector is gaining increasing attention in the energy and efficiency strategies at European and national level [12].

What do the observations of the electricity transmission network mean, transferred to a SR-DHN? What has changed when the electricity transmission network was installed in contrast to previous island power networks? The results in Table 2 are based on discussions in two expert workshops.

\subsection{Technical Results}

This subsection addresses summer heat sinks, design and operation. 


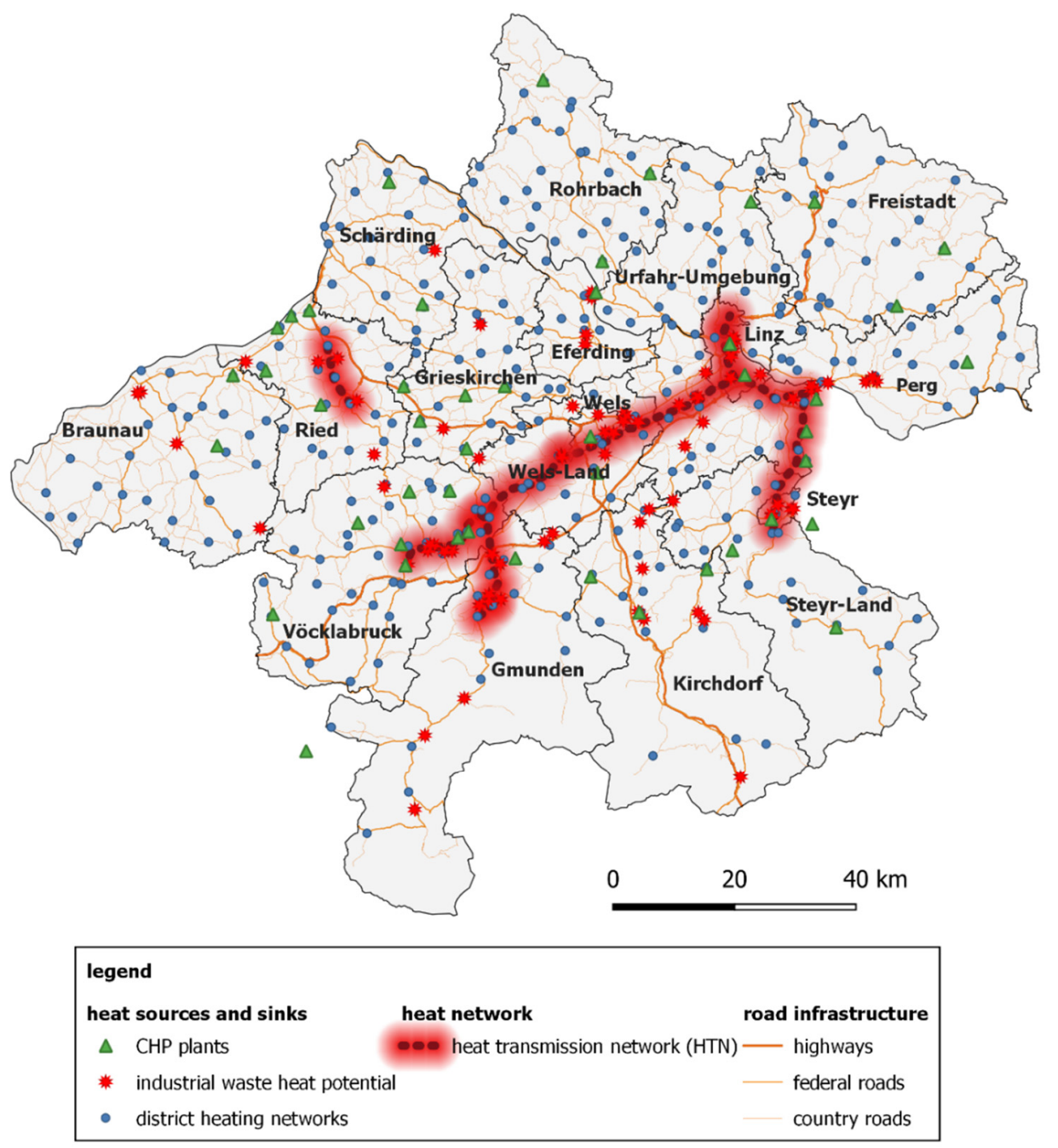

Figure 2. Case study results: possible routing of a SR-DHN in Upper Austria [31].

\subsubsection{Integrating and Enabling New (Summer) Heat Sinks}

Industrial waste heat potentials are relevant the whole year, but especially high in summer (see [2] and Section 4.1). Of course, this supply faces little demand in summer. Due to the limited heat and hot water demand, district heating networks cannot make use of all the excess heat from waste incineration plants, the electricity-market driven operation of gas CHP plants and industrial waste heat in summer. This results in high available heat amounts and heat loads, with significant shares to be expected at high temperature levels. For the use of industrial waste heat, integrating new consumers will play a central role, and their demand should thus go beyond satisfying buildings' hot water needs; in this regard, experts consider the following consumers to be interesting:

(Seasonal) heat storages: Industrial waste heat is primarily available in summer months, but district heating demand mainly occurs in winter months. In order to shift heat potentials from summer to winter and thereby make the feed-in of industrial waste heat economically more attractive (as it is used in summer too), large-scale (seasonal) heat storages represent an opportunity. Urban property prices are crucial for the total construction costs and currently result in too long payback periods of seasonal heat storages [2]. Locating a seasonal heat storage in rural areas with low land prices traversed by the SR-DHN may enable economic feasibility. Temperature: Large seasonal heat storages are expected not to be pressurized due to their size, and thus shall have a temperature close to $100{ }^{\circ} \mathrm{C}$ in order to store a maximum amount of heat [2]. Consequently, charging requires network flow temperatures of at least $100{ }^{\circ} \mathrm{C}$. 
Table 2. Comparison with electricity transmission networks. Source: stakeholder and expert workshop.

\begin{tabular}{l} 
Observation of Electricity Transmission Networks \\
\hline Large power plants situated as close to the consumption centers as \\
possible form the backbone of today's power supply. Remote large-scale \\
potentials (e.g., hydropower) are connected.
\end{tabular}

Decentralized generation results from decentral potential and cost efficiency, i.e., $\mathrm{PV}$ and wind power plants.
Large powers can be transmitted in both directions.

Equivalent in Hypothetical SR-DHN

Large heating plants close to consumption form the backbone of today's heat supply. Supply lines from remote potentials are partially known (see Section 3), but are not standard.

The SR-DHN's energy transmission performance is much lower. The transmission in both directions may be limited by technical conditions.

Geothermal energy, lower-temperature heat prepared with heat pumps and solar thermal energy as well as waste heat in decentralized companies, which are enabled by a passing SR-DHN route, can then represent cost-efficient potential.

Losses of transmission are significant but not too high. Losses of transmission are likely to be significant and crucial.

Today, large thermal storages are not feasible as the benchmark is burning fossil fuels [2]. In a sustainable energy system, the main storage systems can be large thermal storages, which may be cost-effective in rural areas and can make use of geographic conditions. As is shown in [2], larger storages can also act in the short term for the optimization of CHP plant operation and as backup system at the same efficiency levels as short-term storage. During operation at higher network temperature e.g., $>100^{\circ} \mathrm{C}$, the capabilities and cost-efficiency of water-based thermal heat storages drastically shrink. In this situation, the relevance of booster systems or (more expensive) high-temperature storage systems increases.

Inexpensive heat sources are a precondition for the profitability of storages. Ideally, this implies that losses of charging and storing are economically negligible [2]. Experts agree that the peak heat demand has to be covered by today's heating plants, including or adding power-to-heat systems, acting as backup and being fueled by renewable gases.

The electricity transmission network also made it possible to electrify remote areas. The connection means that no separate investment in own generation capacity is required.

(Small) consumption centers, which are affected by a passing SR-DHN, can then possibly obtain inexpensive heat-as with electricity, no investment in generation is required; the establishment of a local distribution network can thus become cost-effective.

Older small district heating networks often have high losses in summer (low demand, but high network temperatures and circulating water volume). In these cases, moreover, boilers are often operated in the partial load range. The connection to a SR-DHN, which is traversing the small network, can reduce these costs. If there are inexpensive sources connected to the network and there are surpluses, the network can absorb it.
The electricity transmission network made it possible to connect networks that had previously been operated as islands: sale of inexpensive energy, purchase of inexpensive energy, additional security of supply in the event of failure of own production.

Waste-heat-to-cold: Potential customers can be (waste) heat-to-cold systems, i.e., the cooling takes place via absorption heat pumps. Temperature: Waste-heat-to-cold works particularly efficiently when high flow temperatures can be used; temperatures under $100{ }^{\circ} \mathrm{C}$ are technically feasible, but depending on the heat output and the efficiency to be achieved, temperatures up to $170{ }^{\circ} \mathrm{C}$ are mentioned [32].

Low-temperature process heat: Another area of sinks can also be the supply of lowcarbon process heat. Among other, processes at this temperature level can primarily be found in the food and beverage industry (e.g., cooling, drying, boiling, sterilization) but also in the chemical industry and large-scale laundry services. Temperature: The network flow needs to be above the required process temperatures, starting at just under $100{ }^{\circ} \mathrm{C}$ and, depending on the process design, up to $130{ }^{\circ} \mathrm{C}$ for sterilization. Of course, individualized processes may need other temperature levels [33].

More efficient existing small district heating networks: Existing smaller district heating networks traversed by the SR-DHN could benefit. Boilers often operate inefficiently in the partial load range in summer. Moreover, boilers are fired with wood chips or fossil fuels, implying high costs in winter and also in summer, when much of the energy is lost during circulation. SR-DHN can provide waste heat for small district heating networks traversed. Temperature: For this application, summer flow temperatures below $100{ }^{\circ} \mathrm{C}$ are sufficient. 
Newly built small district heating networks: Areas that are traversed by the SR-DHN, which previously did not have a cost-effective heat production, can be supplied from the SR-DHN. This allows new district heating distribution networks to emerge. Temperature: The design of new-built systems is likely to be adopted to the supply parameters, and ideally considers the advantages of a fourth generation low-temperature network [4]. Of course, also fifth generation networks could be supplied in winter; in summer, centralized above-mentioned waste-heat-to-cold systems could also be integrated in such a system.

\subsubsection{Temperatures and Losses}

A central question of the concept of SR-DHN is how it differs from normal district heating networks (which are locally closed). Differences are to be shown here, especially with regard to the possible use of industrial waste heat.

High summer temperatures: The arguments presented on additional sinks, and especially potential summer heat sinks, speak in favor of operating the SR-DHN at the highest temperatures possible in summer. This would be $170{ }^{\circ} \mathrm{C}$ for the above-mentioned cases (see Section 4.3.1), but of course, this is hypothetical and must be optimized on a case-by-case basis, taking into consideration:

- $\quad$ if high-temperature waste heat supply is actually sufficient in summer.

- if such sinks are actually in use and if it is an actual option to supply these from the SR-DHN.

- the volume and value of summer heat losses. Especially when using waste heat, heat costs are relatively low in summer (c.f. [34]), and thus heat losses are inexpensive. However, of course, this statement is only true as long as the volume of losses is not too big. This implies that there is an optimum (which cannot be generalized with this qualitative approach).

- the increase in network costs is associated with higher temperatures, especially when the temperature makes additional insulation necessary and standardized pipes cannot be used.

Consequently, it is not possible to derive a generally valid answer as to what temperature "high" exactly means. The designation "high" is intended to make it specifically clear that, in the case of a network that is heavily based on waste heat, the temperature should/can be higher in summer than in winter, because this is in contrast to the usual operation of district heating networks, which works the other way around.

Low winter temperatures: In winter, there is less industrial waste heat available due to company-internal demands. The CHP plants and heat-only boilers in the urban centers are expected to remain the predominant generation units to cover demand. Then, the SR-DHN could be operated at lower temperatures: Temperatures must be high enough to feed into the connected district heating distribution networks, i.e., SR-DHN flow temperatures must at least be higher than the return temperatures of the connected district heating distribution networks. The exact temperature depends on the case-specific integrability. This helps to:

- $\quad$ provide a high share of the winter baseload.

- allow cost-efficient feeders with rather low but sufficient temperature levels, e.g., lowtemperature industrial waste heat, low temperature heat e.g., from ground sources prepared with heat pumps and geothermal energy to be integrated. Again, the exact temperature depends on the case-specific integrability.

- drastically reduce the heat losses that would arise due to the long distances of the SR-DHN. The value of heat is high in winter, as heat would have to be produced alternatively, and thus heat losses are expensive (c.f. [34]).

- $\quad$ seasonal heat storages can be emptied. As their capacity depends on the volume and the temperature difference between maximum storage temperature and network temperatures, heat storage capacity linearly increases with a decrease in network temperature. Heat pumps can further increase storage capacity, as they can make use of the remaining heat stored that is below network temperature. 
Heat losses: Network heat losses depend on the operating flow and return temperature [35]. This means, a reduction of the networks operating temperature leads to reduced heat losses. In the proposed context of high summer and low winter temperatures, heat losses are likely to be, in absolute values, higher in summer operation than in winter operation.

Average relative heat losses are about 20\% in Denmark, and $9 \%$ in Sweden. This does not imply that Sweden's networks are better insulated, but that comparing networks only on heat loss level can lead to incorrect conclusions. Parameters as flow, return and ambient temperature; diameter and length; heat density, annual heat consumption and heat generation costs are essential and have to be evaluated case-specifically considering the local requirements [36].

The proposed SR-DHN will be newly developed; simulations and optimizations of the network are crucial and have to be conducted to state losses in absolute and relative values. Key considerations include available heat sources and sinks, network length, pipe dimensions, insulation thickness, pipe design (single, twin or triple pipes). Kapil et al. [37] assume, in their calculations, heat losses of $1 \%$ per $\mathrm{km}$ of a low temperature network of $86.5 \mathrm{~km}$ length.

\subsection{Economic Results}

Economic results are subdivided-first, in organization, second, in the topic of ownership and financing, and third, in costs and revenue flows.

\subsubsection{Organization}

An SR-DHN involves numerous and multiple types of players (e.g., the operator of the SR-DHN, operators of distribution networks, feeders, consumers). At the same time, the SR-DHN must represent a reliable infrastructure. In accordance with the electricity transmission network, stakeholders claim case-specific contractual network codes for the SR-DHN, establishing fair rules for market players. Although SR-DHN is not interconnected throughout Europe, network codes (here: contractual agreements on actors' requirements and behavior) must be defied as soon as more than one actor is involved.

The number of actors increases complexity. Not only from an operational perspective, but maybe also in order to simplify business organization (i.e., to establish one point of contact for all stakeholders), some existing examples (e.g., Innsbruck and Copenhagen) installed a SR-DHN operator $[16,17,19]$.

Market rules and network codes must be defined on allowance of access, market entry and exit, feed-in merit order, standards on technical behavior (temperatures, ramps, pressures), backup and redispatch, prices, etc.

\subsubsection{Ownership and Financing}

Because SR-DHN involve several actors, there are no clear and simple business models for individual district heating companies. This is due to established business models (risk avoidance, single ownership model, etc.) and the systemic complexity of SR-DHN (organize multiple players from a technical, economic and social point of view).

For industrial companies, SR-DHN is an overall opportunity to reduce energy losses, operate plants in an optimized manner and generate additional sales. However, in most cases, the incentives will be too small for an industrial company to actively invest in an SR-DHN, in which the own amount of waste heat plays a minor role. There must be clear advantages of specific sections. The situation for industrial companies is similar to a normal district heating feed-in.

Detailed and generalizable results on ownership and financing cannot be derived from literature and stakeholder involvement. Stakeholders expect government support (as a driver and co-financer) to be crucial. 


\subsubsection{Costs and Revenue Flows}

The following subsection describes the most important categories of costs and revenue flows to be associated with an SR-DHN.

Infrastructure costs: So far, long-distance district heating pipes and SR-DHN have hardly been scientifically investigated. Most scientific discussions deal with general district heating systems, with a focus on technological improvements to avoid losses and optimize operations. Today's economic transport limit for steam at temperatures of $120-250{ }^{\circ} \mathrm{C}$ is between 3 and $5 \mathrm{~km}$, while hot water with temperatures of $90-170{ }^{\circ} \mathrm{C}$ can be transported over $30 \mathrm{~km}$. At lower temperatures, the maximum distance is up to $15 \mathrm{~km}$ [38]. Kapil et al. [37] investigated that a distance of $86.5 \mathrm{~km}$ can be reached with $62 \mathrm{MW}$ of low temperature heat (without considering the pump costs). In general, these studies indicate that the estimation of the maximum distance of heat transport is vague, but could be up to $40 \mathrm{~km}$. The main heat sources of the current district heating transmission pipelines and SR-DHN practice examples (see Section 3.2) are CHP plants and waste incineration plants. Waste heat recovery and external use from energy-intensive industrial sectors is increasingly being applied. Average costs of long-distance district heating transmission pipelines as described in Section 3.1 are approximately 1000 Euro/meter in Austria [31]. For a length of $130 \mathrm{~km}$, this results in Euro 130 million. The costs of further investments are considered to be related to, and relevant for, SR-DHN, such as seasonal heat storages or waste-heat-to-cold systems, are of course not included in these prices.

Costs of heat losses: The value of heat losses is defined by the costs of the units currently feeding into the SR-DHN. If the SR-DHN is predominantly fed with waste heat, costs for heat losses are of minor concern. This is likely to be true in summer, while in winter, the costs of the losses are relevant (c.f. [2]).

Operation revenues: The revenues of SR-DHN result from the cost savings of the individual distribution networks or heat sinks compared to their current benchmark. The revenues are to be calculated on a case-by-case basis and depend on the potentials/costs of the actors involved. These actors define the heat merit order and the advantages of the current heat price in the SR-DHN compared to the production in the previous benchmark. For the exact calculation of the advantages, the individual variable costs of the involved actors have to be known. The cost of the feed-in (e.g., of industrial waste heat) must be known. This is neither given theoretically nor in the case study that was carried out, which means that there is no possibility of determining current sales from operations. The determination of the benchmark is also complex, as this would need to take into account the electricity market and must therefore have a resolution of $15 \mathrm{~min}$ (c.f. [34]). One simple estimation approach is to determine the variable heat price using gas costs. To do this, the current gas price, network costs and taxes would have to be used to calculate a heat price, taking efficiency into account. The compensation for the waste heat feeder would have to be deducted from this heat price. If 5-25 Euro/MWh (as a range from appreciative remuneration to the full gas price, see EEX for April 2021, adding Austrian gas tax) remain as revenue and 300-800 GWh/a (representing figures for a low and an above-average feed-in situation in the case study) are transported via the SR-DHN, this results in an income of 1.5-20 million Euro per year.

Risk abatement: Most technologies that are required for waste heat recovery and reuse are researched and proven in practice ([39] references some examples). These technologies are identical for internal and external use, i.e., crossing property boundaries alone does not influence technologies and associated costs. As waste heat recovery within a company can be considered as an already wide-spread practice, there must be other barriers to external reuse. From an economic point of view, in the profitability calculation, uncertainties must be taken into account. Some of these uncertainties refer to the necessity of clearly estimable additional investment costs like backup systems; others refer to informational risks (actual status of the cooperation partner in regard to liquidity, relocation plans, process modification) and market risks (variation of energy market prices). As in the case of stock market shares, risks increase the interest rate and thus shorten the required payback 
period [27]. Multiple sources of waste heat in a portfolio decrease the accumulated risk. Consequently, SR-DHN would allow longer payback periods for single (industrial) waste heat feed-in connections. SR-DHN can thus be an enabler for using industrial waste heat.

\section{Conclusions}

As of today, most district heating networks are operated separately, i.e., without any interaction in-between them. In most cases, fossil fuel or biomass-fired boilers and CHP plants are the backbone of supply. They thus constitute the benchmark for the costs of heat supplied to the local district heating networks. Moreover, district heating network operators rely on established business models (risk avoidance, single ownership model, etc.) and low (market) energy prices. Thus, at best, connecting single networks or connecting even large waste heat sources remains at the edge of profitability.

In order to remain competitive, SR-DHN must offer significant advantages. Contrariwise, investment costs in SR-DHN pipes are large and must be paid back (only) through the spread between the heat costs from the SR-DHN and the existing benchmark plants [34]. Moreover, systemic complexity of SR-DHN (organize multiple players from a technical, economic and social point of view) entails further risks, making SR-DHN less attractive. The complexity of SR-DHN was shown on a qualitative basis. Given today's energy mix, with a high share of generation from fossil fuels, the prospects for widespread use of SR-DHN are modest.

However, considering the Paris Agreement and the European Union's Green Deal communication (COM/2019/640 final), implying the long-term realization of a renewable and highly efficient sustainable energy system, an actual implementation appears realistic. In general, stakeholders see economic feasibility, especially in the case of higher energy prices (e.g., due to carbon abatement regimes), as using waste heat and integrating of yet unused potentials may become cost-effective then. For a given heat generation infrastructure, investment costs of a SR-DHN are not exorbitant, e.g., they are comparable to gas-fired CHP units. In order to be economically efficient, SR-DHN must absorb the most inexpensive sources of heat, e.g., waste heat, which is supra-regionally available and must sell heat at the highest possible price. Supplementary systems like seasonal heat storages and the integration of summer heat customers are likely to be essential for economic feasibility. The above results naturally focus on the Austrian conditions, but the authors consider the results and parameters as sufficient indication to analyze these in other European regions. Thus, future research shall elaborate the investment costs in more detail and estimate the net revenues during operation. For the latter, national circumstances must be taken into account, e.g., heating degree days, legal requirements for profitability calculation, requirements for avoiding climate change, etc.

Many actors feeding in, storing and consuming energy are involved. They should be given the maximum degree of freedom, but must comply with the technical possibilities of the SR-DHN. In other words, the operation needs to be clearly structured and contractually organized, setting up a framework with network-specific (but probably replicable) network codes and market rules. Future research shall clarify the technical limitations and arrange a replicable legal framework for network codes.

In summer, the large feed-in potential of renewable sources such as solar thermal, geothermal, waste heat from industries (and remaining waste heat from necessary CHP plant operation) contrasts with low demand, thus, heat is likely to be rather inexpensive and consequently, heat losses are inexpensive. SR-DHN can then be operated on with higher temperatures, enabling solutions like waste-heat-to-cold, the supply of industries with low-temperature process heat, the supply of smaller networks (replacement of inefficient boilers in the partial load range) or seasonal storages. In winter, it is not possible to replace the existing generation units, especially during times of peak demand. (Generally, experts see the necessity that these generation units remain as backup.) As the operation of the existing generation units in winter is considered necessary anyhow, temperatures need not ultimately be supplied via the SR-DHN, thus SR-DHN could operate at lower 
temperatures in winter. Therefore, the seasonal storage, lower-temperature industrial waste heat and lower-temperature heat prepared by heat pumps can be used in winter, eventually being fed into the return line. This implies that for SR-DHN predominantly relying on waste heat, the strategy of operation (today: hot in winter, warm in summer) must be reconsidered: There is no need for additional low-temperature heat in summer. From this, the hypothesis is derived that network temperatures should be changed to hot in summer, warm in winter. If this reverse temperature mode of operation, which was derived from the qualitative approach explained in Section 4.3, is feasible in practice, it should be subject to further research.

Author Contributions: For Conceptualization, S.M.; methodology, S.M. and S.P.; validation, S.M. and S.P.; formal analysis, S.M. and S.P.; investigation, S.M. and S.P.; writing—original draft preparation, S.M. and S.P.; writing — review and editing, S.M.; visualization, S.P.; supervision, S.M. All authors have read and agreed to the published version of the manuscript.

Funding: The projects this research results from were funded by the State of Upper Austria (project "Fernwärme-Übertragungsnetze" [31]) and by the Climate and Energy Funds and the State of Upper Austria (project "Heat Highway", FFG-number 880797).

Data Availability Statement: Not applicable.

Conflicts of Interest: The authors declare no conflict of interest.

\section{References}

1. Buzna, L.; Issacharoff, L.; Helbing, D. The evolution of the topology of high-voltage electricity networks. Int. J. Crit. Infrastruct. 2009, 5, 72-85. [CrossRef]

2. Moser, S.; Mayrhofer, J.; Schmidt, R.-R.; Tichler, R. Socioeconomic cost-benefit-analysis of seasonal heat storages in district heating systems with industrial waste heat integration. Energy 2018, 160, 868-874. [CrossRef]

3. Holmgren, K. Role of a district-heating network as a user of waste-heat supply from various sources-the case of Göteborg. Appl. Energy 2006, 83, 1351-1367. [CrossRef]

4. $\quad$ Lund, H.; Werner, S.; Wiltshire, R.; Svendsen, S.; Thorsen, J.; Hvelplund, F.; Mathiesen, B.V. 4th Generation District Heating (4GDH): Integrating smart thermal grids into future sustainable energy systems. Energy 2014, 68, 1-11. [CrossRef]

5. Piacentino, A.; Duic, N.; Markovska, N.; Mathiesen, B.; Guzović, Z.; Lund, V.E.U.H. Sustainable and cost-efficient energy supply and utilisation through innovative concepts and technologies at regional, urban and single-user scales. Energy 2019, 182, 254-268. [CrossRef]

6. Fernwärme, St. Pölten, GmbH, Da Kommt Die Wärme Her-Fernwärme St. Pölten. Available online: https:/ /www.fernwaermestp.at/fernwaerme/da-kommt-die-waerme-her/ (accessed on 26 February 2019).

7. Mein Bezirk. Fernwärme aus Gratkorn für Graz: Kooperationsprojekt gestartet. Available online: https://www.meinbezirk.at/ graz/c-lokales / fernwaerme-aus-gratkorn-fuer-graz-kooperationsprojekt-gestartet_a2312852 (accessed on 8 July 2019).

8. Bioenergie Fernwärme BWS GmbH. Sappi Austria Produktions-GmbH \& Co. KG, Ihr Wärmevorteil aus Gratkorn. Available online: https:/ / www.publicconsulting.at/fileadmin/user_upload/pics/allgemein/News/Expertinnentag_Vortrag_Edler.pdf. (accessed on 8 July 2019).

9. 5min. Fernwärmeleitung von Arnoldstein nach Villach. Available online: https://www.5min.at/201809165441/fernwaermeleitungvon-arnoldstein-nach-villach/ (accessed on 5 April 2019).

10. Fachverband der Gas- und Wämeversorgungsunternehmungen. Industrielle Abwärme für Trofaiach. Available online: https: / / www.fernwaerme.at/aktuell/77/ (accessed on 8 July 2019).

11. APA-OTS, Salzburg AG: Wärmeschiene Hallein—Salzburg mit Energiepreis ausgezeichnet. Available online: https://www.ots. at/presseaussendung/OTS_20050512_OTS0152/waermeschiene-hallein-salzburg-mit-energiepreis-ausgezeichnet (accessed on 21 January 2021).

12. Kavvadias, K.; Quoilin, S. Exploiting waste heat potential by long distance heat transmission: Design considerations and techno-economic assessment. Appl Energy 2018, 216, 452-465. [CrossRef]

13. CEZ Group. The Melnik Power Station. Available online: https://www.cez.cz/en/power-plants-and-environment/coal-firedpower-plants/cr/melnik.html (accessed on 15 July 2019).

14. Konstantin, P. Praxisbuch der Fernwärmeversorgung; Springer: Berlin/Heidelberg, Germany, 2018.

15. ORF Tirol. Fernwärmenetz von Innsbruck bis Wattens. Available online: https://tirol.orf.at/news/stories/2804303/ (accessed on 25 February 2019).

16. TIGAS-Erdgas Tirol GmbH. Inbetriebnahme Fernwärmeschiene Innsbruck-Wattens. Available online: https://www.tigas.at/ index.php/unternehmen/presse-news/11-aktuelles/28-inbetriebnahme-fernwaermeschiene-innsbruck-wattens (accessed on 25 February 2019).

17. TIGAS-Erdgas Tirol GmbH. Wärme für Tirol—Geschäftsbericht 2017; TIGAS: Innsbruck, Austria, 2017. 
18. Bjørn, H.; Kristensen, K.; Hammer, F. District heating based on surplus energy. Int. Mag. Dist. Heat. Cool. 2009, 2 , 6-7.

19. Danish Board of District Heating. District Heating History. Available online: https://dbdh.dk/dhc-in-denmark/district-heatinghistory/\#no_08 (accessed on 21 January 2021).

20. Fernwärmeschiene Rhein-Rhur GmbH. Die Fernwärmeschiene Rhein-Ruhr-ein Leuchtturmprojekt in Europa. Available online: https: / / www.fwsrr.de/auf-einen-blick/referenzprojekt-europas / (accessed on 12 July 2019).

21. Stadtwerke Dinslaken GmbH. Fernwärmeverbund Niederrhein Duisburg/Dinslaken GmbH \& Co. KG. Available online: https: / / www.stadtwerke-dinslaken.de/privatkunden/fernwaerme/fernwaerme-uebersicht/wir-ueber-uns/fernwaermeschieneniederrhein/fernwaermeverbund-niederrhein-duisburgdinslaken-gmbh-co-kg.html (accessed on 21 January 2021).

22. Stadtwerke Dinslaken GmbH. Die Fernwärmeschiene Niederrhein. Available online: https://www.stadtwerke-dinslaken de/privatkunden/fernwaerme/fernwaerme-uebersicht/wir-ueber-uns/fernwaermeschiene-niederrhein.html (accessed on 21 January 2021).

23. STEAG Fernwärme GmbH. Fernwärme für eine umweltfreundliche Wärmeversorgung. Available online: https: / /www.steag. com/uploads/pics/STEAG_FactSheet_Fernwaerme.pdf (accessed on 27 February 2019).

24. EnergieAgentur.NRW. Machbarkeitsstudie Fernwärme im Ruhrgebiet. Für Energieeffizienz und Klimaschutz; EnergieAgentur.NRW: Düsseldorf, Germany, 2019.

25. European Commission. Background Report on EU-27 District Heating and Cooling Potentials, Barriers, Best Practice and Measures of Promotion; Publication Office of the European Union: Luxembourg, 2012.

26. Fernwärme-Verbund Saar GmbH. Die Fernwärmeschiene Saar-Broschuere. Available online: https://www.fvs.de/index.php? $\mathrm{id}=1782 \& \mathrm{~L}=0$ (accessed on 26 February 2019).

27. Moser, S.; Lassacher, S. External use of industrial waste heat-An analysis of existing implementations in Austria. J. Clean. Prod 2020, 264. [CrossRef]

28. Renewables4Industry. Diskussionspapier; Energieinstitut an der Johannes Kepler Universität Linz: Linz, Austria, 2017.

29. Association of Austrian Industries. Industrie und was dazu gehört. Available online: https://oberoesterreich.iv.at/de/ industrieland-oo/industrie-und-was-dazu-gehort (accessed on 14 April 2020).

30. Austrian Heat Map. Fernwärme und Kraft-Wärme-Kopplung in Österreich, Bundesministerium für Nachhaltigkeit und Tourismus. Available online: http:/ / www.austrian-heatmap.gv.at/das-projekt/ (accessed on 22 January 2020).

31. Puschnigg, S.; Moser, S.; Mendez, E.D. Fernwärme-Übertragungsnetze; Energieinstitut an der Johannes Kepler Universität Linz: Linz, Austria, 2020.

32. Kalkgruber, J. Aufbau und Inbetriebnahme einer Absorptionswärmepumpe zur Untersuchung von Ammoniak-Wasser-Natriumhydroxid Gemischen; TU Graz: Graz, Austria, 2009.

33. Lassacher, S.; Puschnigg, S.; Lindorfer, J. Technische Aspekte der Forcierung von Primärenergieeffizienz an oberösterreichischen Produktionsstandorten durch Nutzung von Wärmespeichern; Energieinstitut an der Johannes Kepler Universität Linz: Linz, Austria, 2018.

34. Moser, S.; Puschnigg, S.; Rodin, V. Designing the Heat Merit Order to determine the value of industrial waste heat for district heating systems. Energy 2020, 200. [CrossRef]

35. Lund, H.; Østergaard, P.; Chang, M.; Werner, S.; Svendsen, S.; Sorknæs, P.; Thorsen, J.; Hvelplund, F.; Mortensen, B.; Mathiesen, B.; et al. The status of 4th generation district heating: Research and results. Energy 2018, 164, 147-159. [CrossRef]

36. Masatin, V.; Letosev, E.; Volkova, A. Evaluation factor for district heating network heat loss with respect to network geometry. Energy Procedia 2016, 95, 279-285. [CrossRef]

37. Kapil, A.; Bulatov, I.; Smith, R.; Kim, J. Process integration of low grade heat in process industry with district heating networks. Energy 2012, 44, 11-19. [CrossRef]

38. Ammar, Y.; Joyce, S.; Rosemary, N.; Yaodong, W.; Roskilly, A.P. Low grade thermal energy sources and uses from the process industry in the UK. Appl. Energy 2012, 89, 3-20. [CrossRef]

39. Blömer, S.; Götz, C.; Pehnt, M.; Hering, D.; Ochse, S.; Hespeler, S.; Richter, S.; Thomassen, P.; Grytsch, G.G.; Zopff, C.; et al. EnEff: Wärme-Netzgebundene Nutzung Industrieller Abwärme (NENIA)—Schlussbericht; IFEU: Heidelberg, Germany, 2019. 